\title{
ANÁLISE DOS DEPÓSITOS DE LATERITAS NIQUELÍFERAS DO BRASIL A PARTIR DO CONCEITO DE SISTEMAS MINERAIS HOLÍSTICOS
}

\author{
Igor Henrique Fernandes Silva ${ }^{1}$ \\ Flávia Cristina Silveira Braga²
}

\author{
10.18190/1980-8208/estudosgeologicos.v30n1p79-99 \\ ${ }^{1}$ Universidade do Estado de Minas Gerais, João Monlevade, Minas Gerais \\ igor_henrique93@hotmail.com \\ ${ }^{2}$ Universidade do Estado de Minas Gerais, João Monlevade, Minas Gerais \\ flaviacsbraga@gmail.com
}

\section{RESUMO}

O conceito de sistema mineral, o qual interpreta os depósitos minerais relacionando-os à dinâmica terrestre, atualmente é utilizado para interpretação da gênese dos depósitos de maneira holística, sendo importante ferramenta para a pesquisa mineral. Nesse sentido, o presente trabalho faz uma interpretação do níquel laterítico segundo preceitos dos sistemas minerais, e aponta áreas potenciais para novas pesquisas no Brasil. Uma das principais fontes de níquel provém de minerais formados por alterações superficiais de rochas ultramáficas submetidas à climas tropicais e à relativa estabilidade tectônica, existindo, no território brasileiro, diversas regiões potenciais. Os melhores protólitos que se tem registro no Brasil são complexos ultramáficos-máficos estratiformes. Entretanto, os complexos ofiolíticos associados às faixas móveis pré-cambrianas, correspondem a um importante ambiente geotectônico que pode hospedar depósitos. Praticamente todos os protólitos brasileiros estão serpentinizados, processo que de certa forma auxiliou na precipicitação e acumulação de níquel dissolvido em ambiente supergênico. Quanto à geomorfologia, o processo está intimamente relacionado com as superfícies de aplainamento. $\mathrm{Na}$ maioria das lateritas niquelíferas brasileiras, as condições paleobioclimáticas submeteram os silicatos primários portadores de níquel das rochas ultramáficas, exumadas pelas superfícies de aplainamento, ao intemperismo químico, ou seja, à hidrólise, forçando a precipitação da Ni-goethita (nível oxidado) e posteriormente à dissolução, reprecipitação e formação das 'garnieritas' (nível silicatado).

Palavras chave: sistema mineral, níquel, lateritização, intemperismo, rochas ultramáficas

\begin{abstract}
The concept of mineral system, which interprets mineral deposits in relation to terrestrial dynamics, is currently used to interpret the genesis of deposits holistically, being an important tool for mineral research. In this sense, the present work makes an interpretation of nickel laterite according to the precepts of mineral systems and points out potential areas for further research in Brazil. One of the main sources of nickel comes from minerals formed by surface changes of ultramafic rocks submitted to tropical climates and relative tectonic stability, with several potential regions in Brazil. The best protoliths that are registered in Brazil are stratiform ultramafic-mafic complexes. However, the ophiolitic complexes associated with the Precambrian mobile belts, correspond to an important geotectonic environment that can host significant deposits. Practically all Brazilian protoliths are serpentinized, a process that supported the precipitation and
\end{abstract}


accumulation of nickel dissolved in a supergenic environment. In term of geomorphology, the lateritization profile is closely related to plane surfaces. In most Brazilian nickeliferous laterites, paleobioclimatic conditions submitted the primary silicates with ultramafic nickel, exhumed by planing surfaces, to chemical weathering, and hydrolysis, forcing the precipitation of Ni-goethite (oxidized level) and subsequently to dissolution, reprecipitation and formation of 'garnieritas' (silicate level).

Keywords: mineral system, nickel, lateritization, weathering, ultramafic rocks

\section{INTRODUÇÃO}

A abordagem dos sistemas minerais para entender os depósitos minerais ganhou aceitação crescente nos últimos 25 anos. Essa abordagem tem origem na indústria petrolífera, em que a ênfase dos estudos está nos processos críticos para a formação de um depósito mineral, na análise da fonte, liberação, migração, caminho, armadilha e trapa (Hagemann et al., 2016; McCuaig et al., 2010).

O conceito de sistema mineral engloba informações que tornam possível a interpretação dos depósitos minerais como sendo originados pela dinâmica terrestre no espaço-tempo, ou seja, busca-se a partir desse conceito um entendimento integral dos fenômenos formadores dos depósitos, para assim selecionar e explorar novos alvos (Hagemann et al., 2016; Groves et al., 2016; McCuaig et al., 2010; Wyborn et al., 1994). Segundo Hagemann et al. (2016), os sistemas minerais visam reconhecer os eventos tectônicos e geoquímicos primários, os mecanismos e fluxos dos fluidos mineralizantes, os processos físico-químicos que causaram a concentração in situ do elemento, os processos pós-concentração que são passíveis de detecção e todos aqueles que auxiliaram de alguma forma na preservação e evolução dos depósitos. Portanto, é feita a análise da formação do minério em resposta à processos geológicos que operam em escala $\mathrm{e}$ prazos muito maiores do que o considerado na maioria dos modelos tradicionais centrados em depósitos
(Hagemann et al., 2016; Barnes et al., 2016).

A abordagem do sistema mineral nasceu da necessidade de aumentar a taxa de sucesso da exploração e exigiu a formulação de modelos de mineralização genéticos que não se concentrassem apenas nos depósitos, mas também integrassem dados locais, de campo e regionais relacionados à mineralização investigada (Hagemann et al., 2016). A aplicação de sistemas minerais mostra-se bastante eficiente quando aplicada em áreas pouco exploradas e com poucos afloramentos, onde modelos empíricos são desenvolvidos, e o mapeamento das expressões dos elementos críticos dos sistemas minerais pode efetivamente focalizar o direcionamento da exploração mineral (Hagemann et al., 2016).

O Brasil devido as suas condições climáticas tropicais e semi-áridas em grande parte do território a partir do final do Cretáceo e relativa estabilidade tectônica, combinadas com a complexidade dos seus terrenos geológicos, proporcionaram a formação de diversos depósitos lateríticos, ainda pouco estudados (Costa, 2007). O país é uma fronteira para pesquisas de novos depósitos minerais em pleno início de século XXI, e as regiões nordeste, centro-oeste e a amazônica constituem as fronteiras mais importantes. O Brasil atualmente situa-se na segunda posição em reservas mundiais de níquel. As reservas brasileiras estão distribuídas entre os Estados de Goiás (77,2\%), Bahia $(12,4 \%)$, Pará $(8,9 \%)$, Minas Gerais $(1,0 \%)$, São Paulo $(0,4 \%)$ e Piauí $(0,1 \%)$. 
Em 2015 o Brasil foi o sexto maior produtor mundial de níquel (DNPM, 2018).

Nesse contexto, o presente trabalho teve como objetivo reconhecer e descrever aspectos gerais do conceito de sistema mineral aplicado aos depósitos minerais de níquel laterítico no Brasil. Uma das principais fontes de níquel provém de minerais formados por alterações de rochas ultramáficas submetidas a climas tropicais e relativa estabilidade tectônica, existindo no território brasileiro diversas regiões potenciais para esse tipo de mineralização.

\section{EXPLORAÇÃO MINERAL E A APLICAÇÃO DOS SISTEMAS MINERAIS}

A exploração mineral é um processo de avaliação de longo prazo, que depende de fatores geológicos, técnicos, ambientais, sociais, políticos, legislativos e econômicos. É um exercício de criatividade intelectual e científica, que envolve inovação e teste contínuo de ideias geradas, além do desenvolvimento de técnicas analíticas (Bettencourt et al., 2016).

Para embasar a prática de exploração mineral, foram criados modelos genéticos de depósitos minerais, os quais estão em constante renovação (Figueiredo, 1992). A partir da segunda metade do século passado, os modelos se tornaram indispensáveis na pesquisa e exploração mineral. Segundo Cox \& Singer (1986), um modelo de depósito mineral consiste em um arranjo sistemático de informações, que descrevem os atributos essenciais (propriedades intrínsecas) de uma dada classe de depósitos minerais. O modelo pode ser: empírico (factual, descritivo ou modelo de ocorrência) que, em si, é desenvolvido a partir de características geológicas mensuráveis e mapeáveis, sendo assim baseado em observações factual; conceitual (genético, interpretativo, causal ou modelos de processos), que deriva de dados do modelo empírico, para identificar processos envolvidos na gênese do minério, baseado em observações e interpretações. Para a criação de um modelo de depósito mineral a ser usado em exploração mineral, os modelos empírico e genético são geralmente combinados (Evans \& Moon, 2006).

Segundo Figueiredo (1992) o modelo descritivo-genético de depósitos minerais compreende a listagem dos atributos reconhecidos como diagnósticos ou essenciais de um tipo de depósito, mesmo que as relações entre esses atributos não sejam claras. Segundo o autor, quando se aplicam os modelos descritivos-genéticos na exploração mineral, muitas vezes, não é dada a devida importância para as relações espaciais e temporais entre os vários tipos de depósitos presentes na mesma unidade geológica-tectônica.

Biondi (2015) trata dos depósitos minerais segundo os conceitos de sistemas, processos mineralizadores e modelos genéticos. Segundo o autor, sistema é a parte do universo que participou da formação do depósito, e o processo mineralizador é um conjunto de ações que levam a formação do depósito. Já o modelo genético ou conceitual de um depósito mineral, segundo o autor, é um modo simplificado e objetivo de explicar como se forma um depósito. É importante destacar que, diferentes processos mineralizadores podem ocorrer em um mesmo sistema e viceversa. $\mathrm{O}$ autor trata os depósitos minerais brasileiros segundo os seguintes sistemas mineralizadores: endomagmático, hidrotermal magmático, hidatogênico, metamórfico, sedimentar e supergênico. Outros livros tais como Arndt \& Ganino (2012) e Ridley (2013) tratam os depósitos segundo quatro grupos: magmáticos, hidrotermais, sedimentares e superficiais e 
supergênicos. Tratam-se de classificações baseadas nos processos de concentração em escala de depósito, com restritas informações sobre sua configuração geodinâmica e conexão dentre províncias (Hagemann et al., 2016).

A compilação de modelos de depósitos minerais é extremamente útil aos estudos de avaliação de recursos minerais e nos trabalhos de prospecção (Bettencourt et al., 2016; Evans \& Moon, 2016; Figueiredo, 1992). São também utilizadas como ferramentas indispensáveis no planejamento do uso e ocupação do solo, no ensino da geologia econômica e para identificar problemas fundamentais para a pesquisa científica (Figueiredo, 1992). No entanto, segundo Bettencourt et al. (2016), o uso de modelos incompletos ou equivocados, aliado a um nível baixo de conhecimento geológico de determinadas regiões, tem resultado em poucos sucessos na exploração mineral.

Embora os modelos de depósitos minerais descritivos e genéticos sintetizem efetivamente características comuns em escala de depósito, eles geralmente falham em prever adequadamente localizações e escalas de depósitos minerais não descobertos - um requisito importante para $o$ direcionamento eficaz da exploração mineral, principalmente em regiões pouco exploradas (Hagemann et al., 2016).

Wyborn et al. (1994) define sistema mineral como sendo todos os fatores geológicos que controlam a geração e preservação do depósito mineral, com ênfase nos processos que estão envolvidos na mobilização dos componentes do minério da fonte, seu transporte e acumulação em forma concentrada e sua posterior preservação ao longo da história geológica. A vantagem da abordagem do sistema mineral é que esta foca nos processos geológicos críticos necessários para formar um depósito, e não é restrita a elementos descritivos específicos de um estilo de mineralização (Hagemann et al., 2016). O diagrama de escala de tempo e espaço apresentado na Figura 1, ilustra o conceito de um sistema mineral.

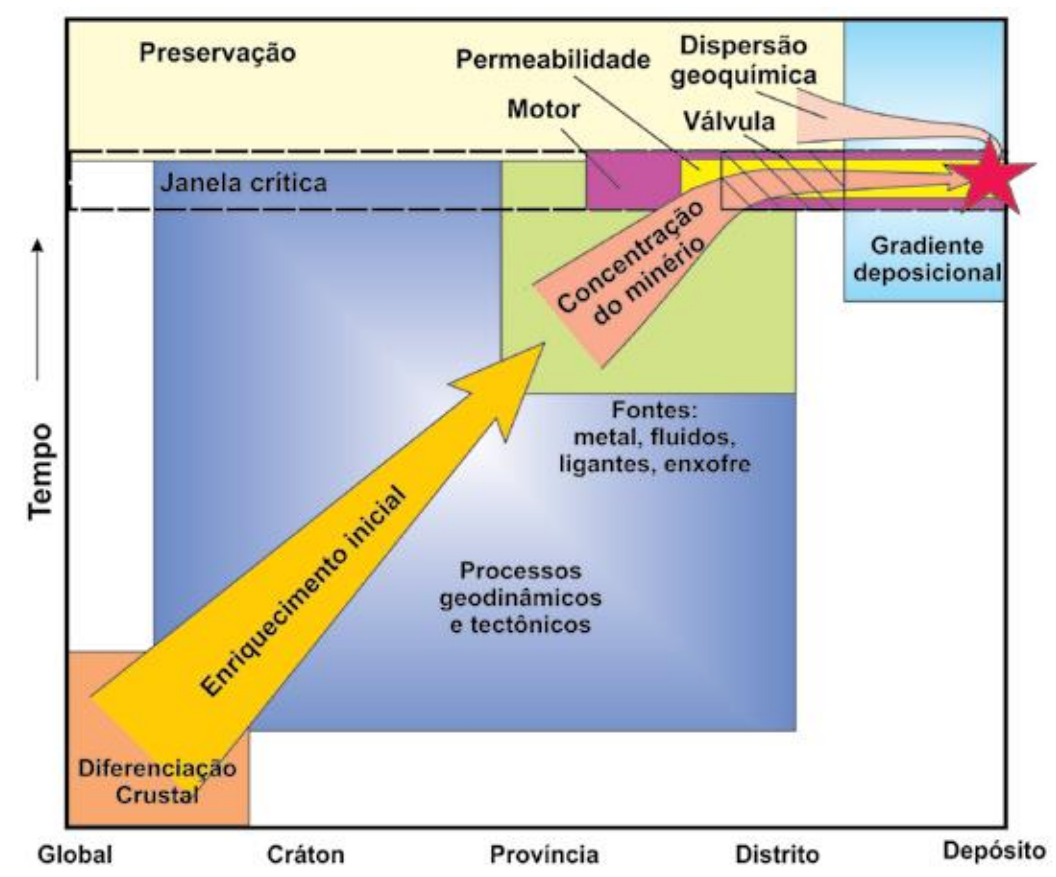

Figura 1. Conceitos envolvidos em sistema mineral, e sua relação com as escalas temporal e espacial. Fonte: Bettencourt et al. (2016). 
McCuaig et al. (2010) determinam as quatro etapas essenciais para vincular os componentes conceituais de um sistema mineral à prática da exploração. Essas quatro etapas incluem: (1) definição dos processos críticos do sistema mineral (o que deve ocorrer para que um depósito mineral se forme); (2) processos constituintes do sistema mineral (várias maneiras pelas quais os processos críticos podem ocorrer); (3) elementos de direcionamento (evidências de que os processos ocorreram) refletidos na geologia e (4) critérios mapeáveis que podem ser usados para detectar os elementos do sistema mineral.

\section{PROTOMINÉRIO}

A sistemática da distribuição dos elementos químicos na rocha mãe e os processos endógenos, ígneos e metamórficos, são cruciais para a compreensão da maior ou menor disponibilidade dos elementos durante a alteração do protólito (Souza et al., 2014). No contexto do sistema mineral do níquel laterítico essa fase representa a diferenciação crustal no espaço e no tempo e o enriquecimento inicial do elemento (Figura 1). A composição da rocha mãe representa, portanto, o controle primário da formação do minério, uma vez que a rocha sob intemperismo deve conter minerais capazes de liberar níquel de sua estrutura (Brand et al., 1998).

As lateritas niquelíferas, notadamente, são formadas a partir do intemperismo de rochas ultramáficas. Essas concentrações secundárias de $\mathrm{Ni}$ (contendo geralmente Co associado), para serem caracterizadas como um recurso econômico, requer que os protólitos sejam moderadamente enriquecidos em Ni (Marsh \& Anderson, 2011). As rochas mais comuns como protólitos do Ni laterítico são dunitos, peridotitos, harzburgitos e wehrlitos em sequências ofiolíticas, komatiítos ricos em olivina e intrusões máficasultramáficas em embasamento précambriano (Brand et al., 1998; Oliveira et al., 1992).

A rochas ultramáficas podem conter até $0,3 \%$ de níquel, predominantemente presente na estrutura de minerais ferro-magnesianos, onde se apresenta sob solução sólida juntamente com o Fe e Mg (Lelong et al., 1976). O alto teor de $\mathrm{Ni}$ nas olivinas (3000-4500 ppm), espinélios (3000$3500 \mathrm{ppm})$ e minerais do grupo dos ortopiroxênios (650-1000 ppm) enfatizam sua alta afinidade pelos primeiros minerais formados durante cristalização fracionada magmática (Burns, 1970; Trescases, 1997).

\section{PROCESSOS DE ENRIQUECIMENTOS SUPERGÊNICO}

As rochas ultramáficas possuem uma mineralogia primária essencialmente anidra, portanto, muito pouco estável sob quaisquer condições de metamorfismo e intemperismo (Strieder, 2017). Os processos metamórficos e deformacionais fazem com que a mineralogia original seja alterada, com geração de minerais hidratados, tais como serpentina, anfibólio e talco (Strieder, 2017).

O conhecido processo de serpentinização, por se tratar de um processo de hidratação da rocha, gera uma expansão na mesma, aumentando o volume entre $25 \%$ e $45 \%$ para uma serpentinização completa (Wicks \& Whittaker, 1977). Esse fato torna a rocha extremamente fraturada e mais reativa aos processos químicos do intemperismo.

As rochas fraturadas apresentam maior permeabilidade, o que aumenta sua taxa de intemperismo. Este processo, por sua vez, forma depressões e pináculos na interface entre a rocha 
fresca e a rocha intemperizada, que se comportam como trapas para a precipicitação e acumulação do $\mathrm{Ni}$ dissolvido (Tomazoni Neto, 2011), conforme ilustra a Figura 2.

A mineralização é dada por uma associação altamente variável de óxidos de Fe- (Mn, Ni, Co), silicatos hidratados de $\mathrm{Ni}-\mathrm{Mg}-(\mathrm{Co})$, sílica amorfa, serpentina, esmectitas, argilominerais, carbonatos e goethita, que vai depender, principalmente, da mineralogia da rocha- mãe, das configurações climáticas e de sua evolução temporal (Brand et al., 1998; Marsh \& Anderson, 2011). Existem três tipos gerais de minérios, baseados nos minerais que contêm o $\mathrm{Ni}$ em sua estrutura cristalina: óxidos, silicatos hidratados de magnésio e argilo-silicatos que se dividem em zonas nos perfis (Berger et al., 2011; Golightly, 2010; Brand et al., 1998), ilustrados na Figura 2

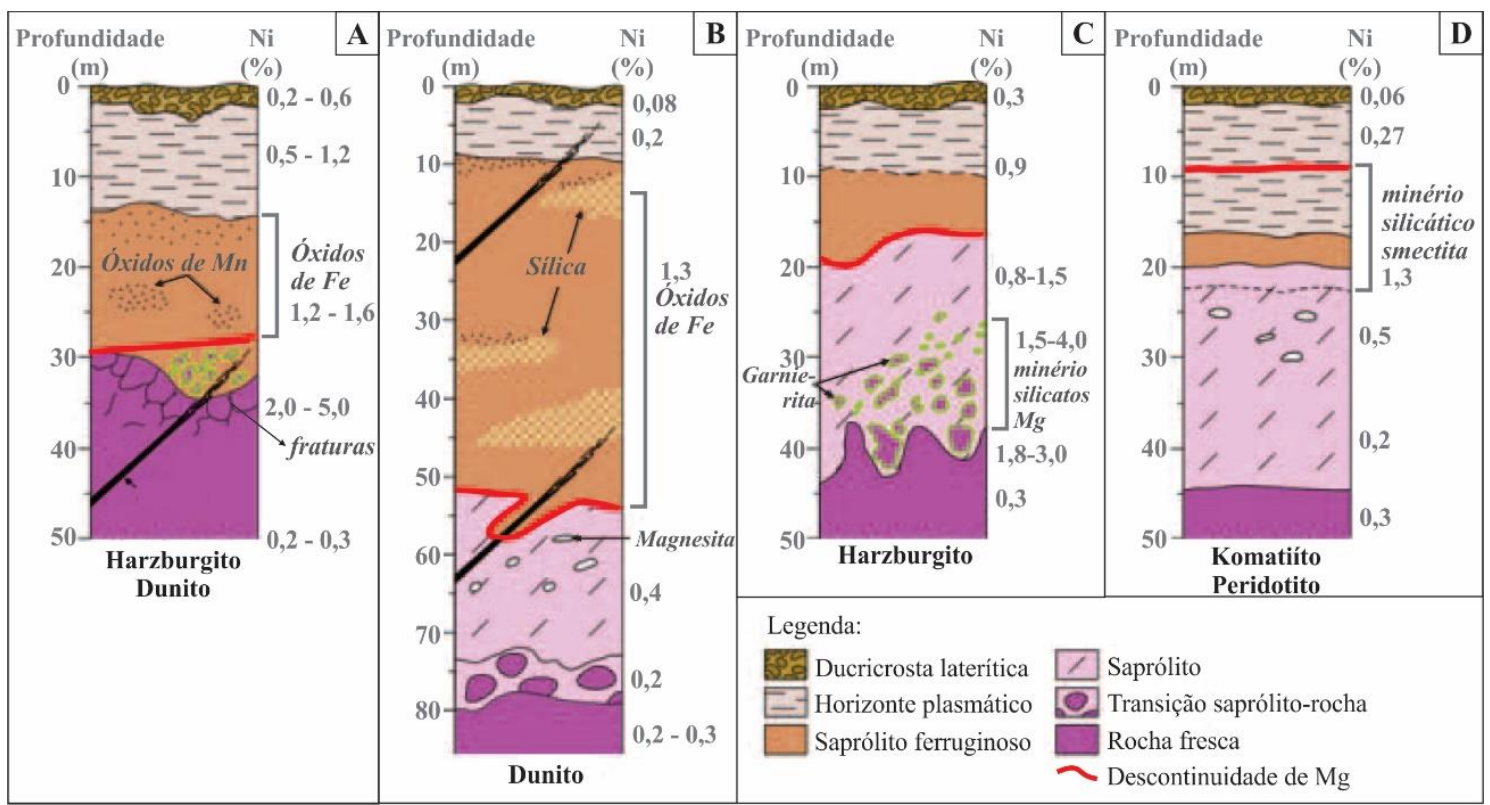

Figura 2. Divisões do perfil laterítico desenvolvido em rocha ultramáfica serpentinizada mostrando os principais minérios de níquel laterítico. (A) óxido; (B) óxido parcialmente silicificado; (C) silicatos de magnésio hidratados; (D) argilominerais. Fonte: modificado de Butt \& Cluzel (2013).

\section{ASPECTOS \\ GEOMORFOLÓGICOS E CLIMÁTICOS BRASILEIROS}

As concentrações lateríticas estão associadas principalmente a formas de relevo aplainadas, restos de paleosuperfícies de intemperismo cobertas por latossolos concrecionais que atuam como blindagem, impedindo a erosão do perfil e a dispersão de elementos (Melfi et al., 1980, Oliveira et al., 1992).
As superfícies de aplainamento são áreas de dimensões continentais, planas ou levemente onduladas, resultantes da erosão subaérea que trunca, indistintamente, rochas e estruturas geológicas de origem e resistência diferentes (Ollier, 1981). Trata-se de uma feição geomorfológica evidente nas margens continentais passivas (Corrêa \& Mendes, 2002).

Segundo Oliveira (1990) a intepretação local do relevo é importante uma vez que os maciços ultramáficas 
podem corresponder a uma colina de corpo tubular, a platôs dissecados ou a serras. Outro ponto destacado por Oliveira (1990) é o grau de dissecação. Quando o relevo é pouco dissecado, as zonas mais mineralizadas situam-se nos topos e encostas, caso contrário, se o relevo for mais dissecado o níquel tenderá a se concentrar nas superfícies mais rebaixadas da topografia.

Fundamentado nas superfícies de aplainamento na África e no Brasil Oriental, King (1956) criou um modelo constituído por superfícies escalonadas, identificando as Superfícies de Erosão no Brasil na seguinte ordem: Superfície Fóssil (Período Carbonífero); Superfície Desértica (Triássico); Superfície PósGondwana ou Superfície Gondwana (Cretáceo); Peneplanação SulAmericana (Paleoceno-Eoceno) seguido por um soerguimento (Oligoceno); Ciclo Velhas (Mioceno-Plioceno) e Ciclo Paraguaçu (Pleistoceno-Holoceno). Nesse contexto, grande parte da área do território brasileiro permaneceu soerguida e em acelerado processo desnudacional desde o Paleozoico. Esses eventos podem ter sido os responsáveis pelo intenso processo desnudacional causador da erosão de espessas sequências de rochas e pela exumação de complexos litoestruturais consolidados em níveis crustais mais profundos (Lima \& Valadão, 2002). Os maciços ultramáficos portadores de depósitos lateríticos no Brasil encontram-se relacionados às superfícies Velhas e Sulamericana, em função de estarem mais ou menos erodidos (Oliveira, 1990).

A maioria dos depósitos de $\mathrm{Ni}$ laterítico do mundo ocorre nos trópicos úmidos atuais (Figura 3). Muitos dos depósitos da Indonésia e alguns na África Ocidental e América do Sul ocorrem em climas de floresta tropical caracterizados por precipitações acima de $1.800 \mathrm{~mm}$ de chuva por ano e estações secas de menos de 2 meses. A maior parte dos depósitos, no entanto, incluindo aqueles na Nova Caledônia, Filipinas, nordeste da Austrália, Caribe e muitos no Brasil, estão situados em savanas úmidas sazonais com chuvas de verão de 900 a $1.800 \mathrm{~mm}$ e inverno seco de 2 a 5 meses (Berger et al., 2011). No entanto, é importante destacar que a gênese dos perfis lateríticos em níquel no Brasil não se deu sob as condições climáticas atuais, sendo esta marcante em sua fase final de evolução, conferindo ao depósito algumas características importantes (Oliveira, 1990). Sob essa perspectiva, em regiões de climas mais úmidos, o horizonte oxidado é mais desenvolvido. Thorne $e t$ al. (2012) calculou que Ni-lateritas tendem a se desenvolver onde a precipitação excede $1000 \mathrm{~mm} / \mathrm{ano}$ e as temperaturas mensais variam entre $22 \mathrm{e}$ $31{ }^{\circ} \mathrm{C}$ no verão e 15 a $27^{\circ} \mathrm{C}$ no inverno. 


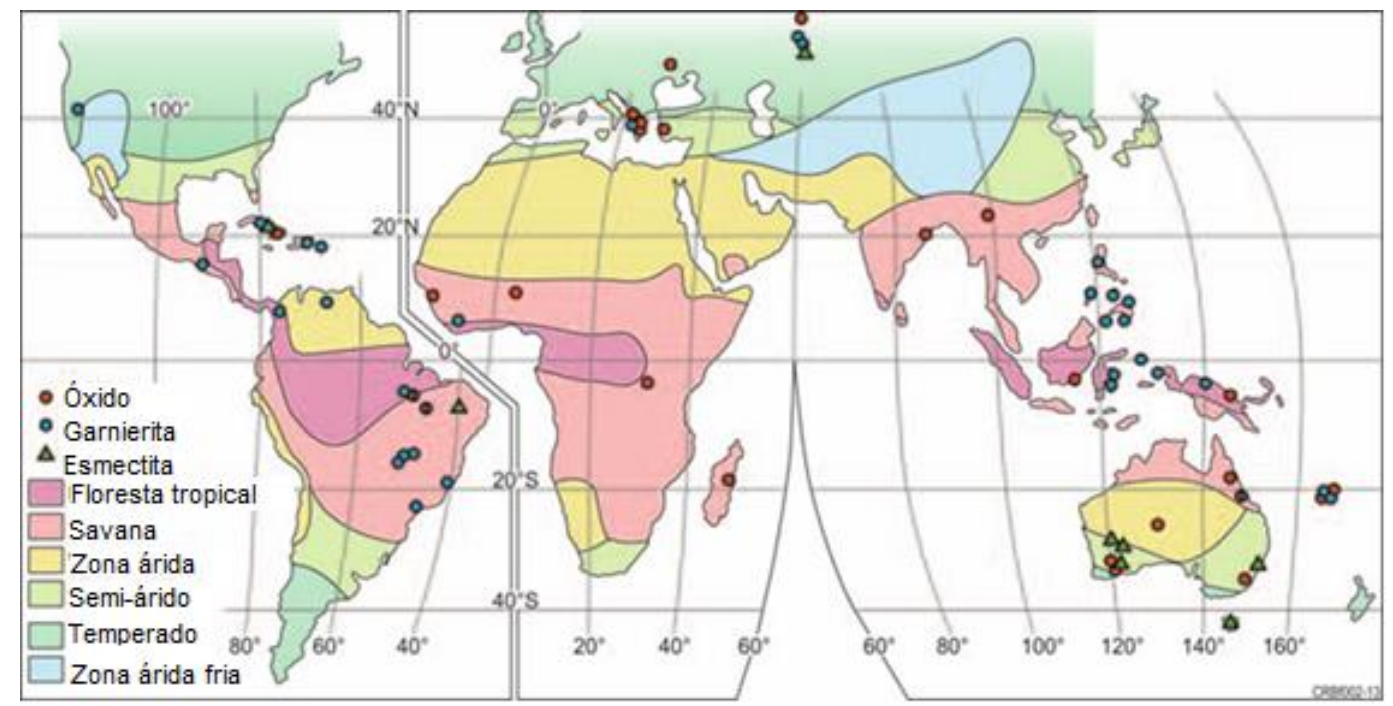

Figura 3. Distribuição mundial dos principais depósitos de Ni laterítico, classificados segundo o principal tipo de minério de níquel (óxido, silicato a garnierita ou esmectita) e zonas morfoclimáticas. Fonte: modificado de Butt \& Cluzel (2013).

\section{PRINCIPAIS DEPÓSITOS DE NÍQUEL LATERÍTICO DO BRASIL}

A seguir são apresentadas as principais características, numa interpretação holística, dos depósitos de níquel laterítico do Brasil (Figs. 4 e 5), com exposição de informações tais como: a província estrutural, descrição dos protólitos e climas condicionantes das mineralizações.

\section{Cráton Amazônico}

No Cráton Amazônico há várias ocorrências de rochas máficasultramáficas, as quais ocorrem intercaladas às sequências metassedimentares ou como intrusões em corpos graníticos, nas regiões norte e noroeste dos estados de Roraima e Amazonas (Maia, 2016).

$\mathrm{Na}$ porção sudoeste do cráton, região denominada de Província Sunsás, há um conjunto de rochas ultramáficas serpentinizadas derivadas de peridotitos (Nunes, 2000; Ruiz et al., 2014). Nessa região estão localizados os depósitos lateríticos de Morro do Leme e Morro Sem Boné, onde as concentrações mais expressivas de níquel encontram-se distribuídas nas zonas saprolíticas do dunito (Ruiz et al., 2014). O depósito Morro do Leme possui reservas totais de $14 \mathrm{Mt}$ com altas concentrações de $\mathrm{Ni}$, atingindo teor de $1,8 \%$ (Louro \& Mantovani, 2012).

$\mathrm{Na}$ Província Carajás, situada na porção leste do Cráton Amazônico, ocorrem intrusões acamadadas representadas pelo Complexo MáficoUltramáfico Serra Leste (Luanga, Formiga e Lago Grande) e pela Suíte Intrusiva Cateté, esta última representada por corpos máficoultramáficos alongados, que recebem a denominação local de Serra do Puma, Serra da Onça, Serra do Jacaré, Serra do Jacarezinho e outros corpos sem denominação formal, os quais, contêm importantes mineralizações de níquel em concentrações supergênicas, elementos do grupo da platina e cobalto associado (Ferreira Filho et al., 2007; Klein \& Carvalho, 2008).

São conhecidos vários depósitos de Ni laterítico associados a Suíte Intrusiva Cateté tais como Puma-Onça, Jacaré-Jacarezinho entre outros (Ferreira Filho et al., 2007; Dardenne \& Schobbenhaus, 2003). O depósito Puma, localizado na serra homônima, é 
caracterizado como um corpo tabular com $27 \mathrm{~km}$ de extensão, largura entre 1,5 e $2,5 \mathrm{~km}$, é acamadado e em sua zona ultramáfica contêm dunitos e peridotitos com intercalações de gabros e lherzolitos (DNPM, 2009). A reserva total calculada é de 53,5 Mt com $1,41 \%$ de $\mathrm{Ni}$ (Dardenne \& Schobbenhaus, 2003). O depósito de Jacarezinho é caracterizado por serpentinitos intemperizados, originados de dunitos de textura cumulática (DNPM, 2009). As jazidas de Jacaré-Jacarezinho apresentam reservas totais de 53,5 Mt, com 1,41\% de $\mathrm{Ni}$ (Dardenne \& Schobbenhaus, 2003).

$\mathrm{Na}$ região de Canaã dos Carajás ocorrem inúmeras associações de rochas máficas-ultramáficas, sendo a mais conhecida a Intrusão Acamadada Vermelho, composta por corpos ultramáficos, essencialmente de dunitos serpentinizados (DNPM, 2009). O depósito do Vermelho possui reserva de $146 \mathrm{Mt}$ com teores médios de $1,05 \% \mathrm{Ni}$ e $0,05 \%$ Co. (Horizonte Minerals, 2020).

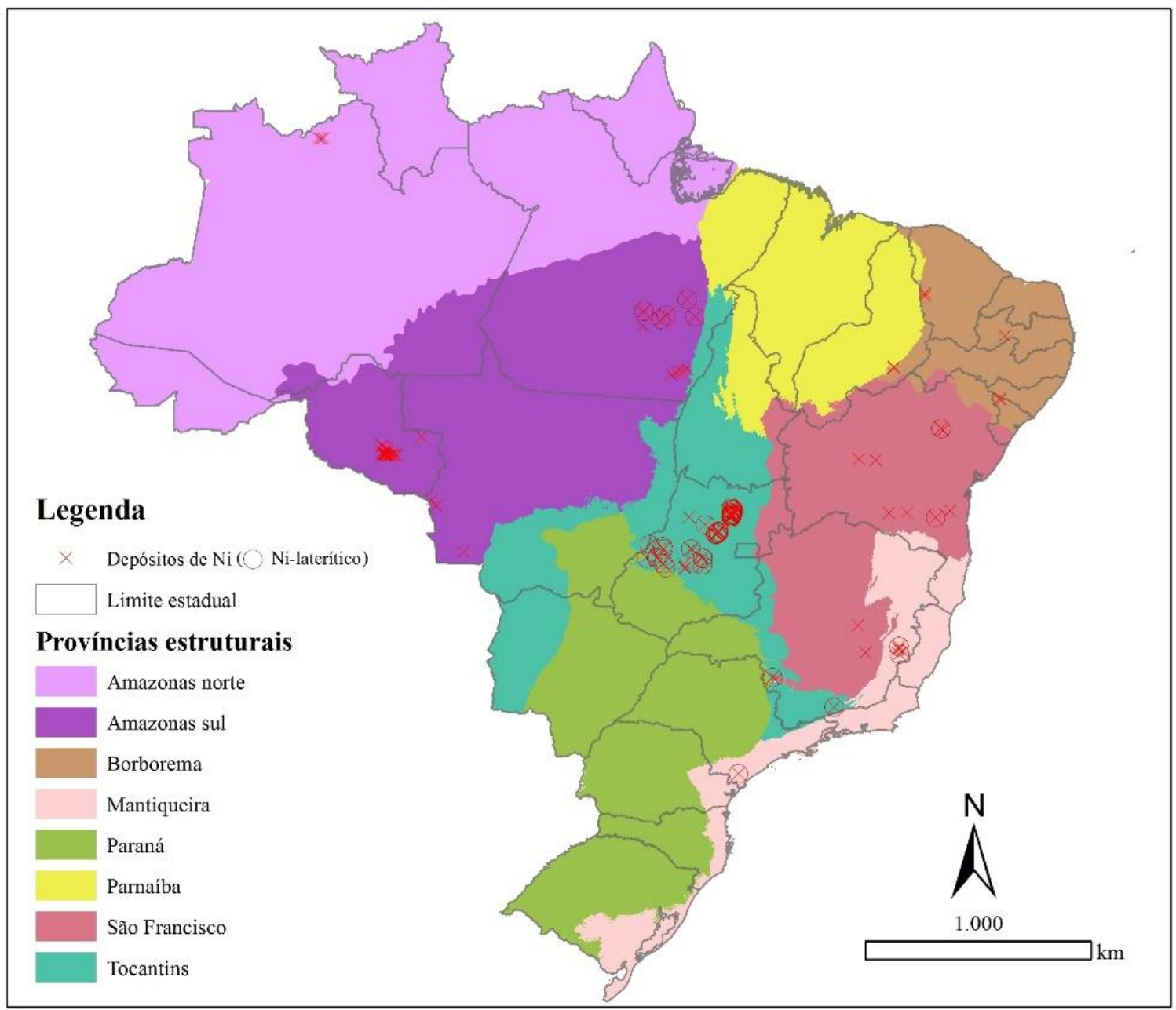

Figura 4. Mapa com localização das províncias tectônicas brasileiras e a principais ocorrências de níquel. Fonte dos dados: CPRM (2001). 


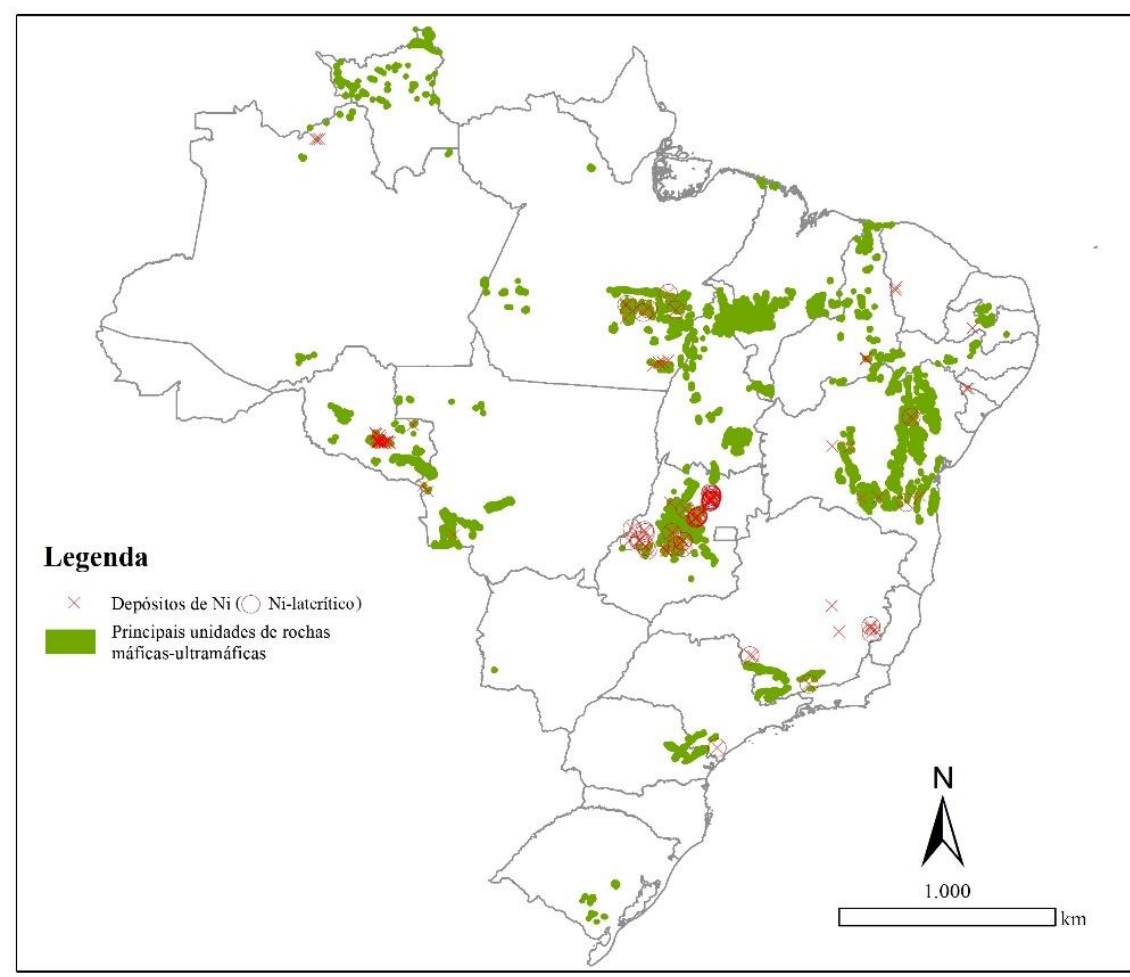

Figura 5. Mapa com localização das principais unidades de rochas máfica-ultramáficas do Brasil e as principais ocorrências de níquel. A dimensão dos corpos foi aumentada para facilitar visualização. Fonte dos dados: CPRM (2001).

\section{Cráton São Francisco}

$\mathrm{Na}$ região nordeste do cráton, no estado da Bahia, ocorre a intrusão máfica-ultramáfica Fazenda Mirabela, onde se intercalam sequências de harzburgitos e ortopiroxenitos que hospedam mineralizações de sulfetos de $\mathrm{Ni}-\mathrm{Cu}$ (Depósitos Peri-Peri e Santa Rita), com corpos menores de $\mathrm{Ni}$ laterítico associados aos cumulados ultramáficos (Matta, 2016; Barnes et al., 2011). Ainda no estado da Bahia existem pequenas ocorrências de níquel laterítico garnierítico na Serra das Marrecas, no norte do estado, já intensamente erodido (CPRM, 2001; Oliveira et al., 1992).

No limite entre o Cráton do São Francisco e a Faixa Brasília são encontrados os depósitos de níquel O'Toole e Morro do Níquel, explorados desde 1962, associados ao greenstone belt Morro do Ferro, sendo o primeiro sulfetado e o segundo laterítico (Dardenne \& Schobbenhaus, 2003). Os protólitos do depósito laterítico Morro do Níquel representam a base do greenstone belt, composto por derrames komatiíticos intercalados com rochas tufogênicas aluminosas, cherts, formações ferríferas e grauvacas (Teixeira \& Dani, 1979).

\section{Principais corpos máficos- ultramáficos em faixas móveis}

Remanescentes de crosta oceânica ocorrem, na maior parte das vezes, nas faixas orogênicas Brasilianas (Províncias Tocantins, Borborema e Mantiqueira), como sequências ofiolíticas. Os ofiolitos brasileiros são, predominantemente, representados por rochas metaultramáficas plutônicas, acamadadas ou maciças, alóctones, e ocorrem como corpos desmembrados, pequenos e tectonicamente intercalados com sequências 
metavulcanosedimentares ou metassedimentares (Queiroga et al., 2012). Geralmente, esses corpos exibem metamorfismo de fácies xisto verde a anfibolito, sendo raros os de grau metamórfico mais alto (eclogitos e retroeclogitos), como os localizados nas regiões de São Sebastião do Paraíso e Pouso Alegre, sul de Minas Gerais (Pinheiro \& Suita, 2008).

\section{Província Tocantins}

As manifestações máficasultramáficas mais importantes do ponto de vista geoeconômico são os complexos de Barro Alto, Niquelândia e Cana Brava, presentes no Maciço Goiás, localizado na porção central da província. O Maciço de Goiás é considerado um fragmento crustal de um microcontinente constituído por terrenos granito-greenstone de idade arqueana, acrescidos de ortognaisses paleoproterozoicos, sequências vulcanosedimentares e complexos granulíticos (Fuck et al., 1993). A reserva de minério da região de Niquelândia, distribuída em mais de 20 jazidas, é de aproximadamente de $60 \mathrm{Mt}$ com um teor médio de $1,45 \% \mathrm{Ni}$, e resulta da decomposição de peridotitos e dunitos (DNPM, 2018).

Numerosos corpos máficoultramáficos de caráter ofiolítico formam um extenso alinhamento com cerca de $500 \mathrm{~km}$ de comprimento bordejando o limite leste do Cráton Amazônico (Paixão, 2009; Paixão \& Nilson, 2002; Gorayeb, 1989). Estes corpos são frequentemente estreitos e alongados, estruturados segundo as direções N-S, NNE ou NNW, alguns com dimensões expressivas, e apresentam mineralizações de níquel, representadas principalmente pela Serra do Tapa e Serra do Quatipuru. Os tipos litológicos presentes são peridotitos e dunitos serpentinizados, cromititos e metaultramafitos (Mendonça, 2012).
Segundo Gorayeb (1989) grande parte dos corpos ultramáficos foram sepentinizados e uma proporção de $70 \%$ a $90 \%$ das olivinas dos dunitos e peridotitos foram transformadas para serpentina (lizardita).

Na região da Faixa Brasília, braço sudeste da província Tocantins, localizase o corpo ultramáfico Liberdade. Soares et al. (2018) localizou teores significativos de níquel nas zonas saprolíticas e nos horizontes oxidados de peridotitos típicos de base de sequências ofiolíticas.

\section{Província Mantiqueira}

No leste do estado de Minas Gerais ocorrem pequenas intrusões ultramáficas de dunitos e harzburgitos serpentinizados neoproterozoicas do Grupo Rio Doce, que apresentam mineralizações em níquel. Próximo à cidade de Ipanema, existem vários corpos ultrámáficos, no entanto só o de Santa Cruz e Santa Maria apresentam potencial niquelífero (Angeli, 1988). Segundo Tuller (2000) o conjunto de rochas foi metamorfisado na fácies granulito e quando retrometamorfisado para a fácies xisto verde, ocorreu o serpentinização das rochas ultramáficas.

Souza et al. (2014) estudou a mobilidade no $\mathrm{Ni}$ em rochas ultramáficas do Escudo Sul-Riograndense, no estado do Rio Grande do Sul. Os teores de Ni encontrados em algumas das rochas estudadas são comparáveis aos encontrados em ultramáficas geradoras de jazidas silicatadas no mundo. No entanto, não há registro de concentrações econômicas na região. Fatores como a recorrência de eventos de deformação e metamorfismo que propiciariam a mobilização do níquel na sequência e a ausência de um clima tropical úmido atuante por um longo período de tempo, suficiente para geração de uma evolução supergênica do tipo laterítica, justificam 
a ausência de depósitos na região (Souza et al., 2014; Menegotto, 2018).

No domínio da Faixa Ribeira, porção centro norte da Província Mantiqueira, são conhecidas algumas ocorrências de níquel silicatado derivados da lateritização de pequenos corpos máficos-ultramáficos. De modo geral, o minério corresponde a veios milimétricos a centimétricos de garnierita contidos em serpentinitos e peridotitos (Riccomini et al., 2004; Fonseca et al., 1998).

\section{Província Borborema}

Os domínios morfoclimáticos que atuaram no nordeste brasileiro fizeram com que a erosão prevalecesse sobre a alteração laterítica. Dessa forma quase todos os maciços ultramáficos da província Borborema não contém depósitos lateríticos de níquel (Melfi et al., 1988). As ocorrências mais expressivas da província estão em sua porção meridional, região de Paulistana, Monte Orebe e São João do Piauí, onde ocorrem metamafitos associados a ofiolitos, com baixo a médio grau de metamorfismo, nos quais a zona serpentinítica apresenta um elevado grau de alteração intempérica que proporcionou a formação de espessos perfis lateríticos (Oliveira, 1990; Melfi et al., 1988).

\section{DISCUSSÕES}

O Brasil possui protominérios niquelíferos de excelência em seu território, distribuídos no tempo e em diferentes províncias (Figuras 4 e 5). Grande parte estão serpentinizados, os mais antigos se relacionam a orogênese paleoproterozoica Transamazônica e correspondem a grandes intrusões no Cráton Amazônico como a suíte intrusiva Cateté na sub-Província Carajás, que hospedam importantes depósitos em fase de atividade de lavra.
Outra intrusão também relacionada ao período Transamazônico é a intrusão Cacoal da Faixa Sunsás.

Outros protólitos, principalmente no sudeste e centro-oeste brasileiros, foram formados na diferenciação crustal do ciclo Brasiliano e estão hospedados em faixas orogenéticas como na Província Tocantins (Figura 4), que apresentam intrusões acamadadas de grandes extensões e algumas menores, como as do sul da Faixa Brasília, e ainda pequenos corpos intrusivos encaixados em rochas de alto grau metamórfico da Província Mantiqueira.

Um fato interessante é que corpos ofiolíticos que sofreram lateritização no Cenozoico apresentam grande potencial metalífero para níquel, como os da Faixa Araguaia, Província Tocantins. Já rochas ultramáficas komatiíticas de greenstone belts não parecem possuir potencialidade para ter gerado lateritas niquelíferas consideráveis.

Do ponto de vista petrológico, os protólitos duníticos parecem ser mais propícios do que os piroxenitos, por exemplo, o que pode ser explicado pelo maior conteúdo médio de níquel presente nas olivinas quando se comparado com os piroxênios.

Observa-se a partir da localização das principais ocorrências de níquel do Brasil, com relação as zonas climáticas brasileiras, que a maior parte dos depósitos se localiza na porção de clima tropical de savana (Fig. 6). Este tipo de clima é caracterizado por duas estações bem definidas, uma seca e outra úmida. Em climática árida o intemperismo físico comumente predomina sobre o químico, o que dificulta a formação e preservação de perfis lateríticos. Com relação aos aspectos geomorfológicos brasileiros, observa-se na Figura 7 que a maior parte dos depósitos se encontra no domínio das depressões e planaltos. A evolução e a preservação das lateritas de níquel no Brasil estão intimamente vinculadas à topografia, uma vez que ela está 


\section{Igor Henrique Fernandes Silva e Flávia Cristina Silveira Braga}

diretamente correlacionada ao perfil de drenagens que se relaciona à mobilidade de alguns elementos, e à preservação do perfil laterítico in situ. Por exemplo, em relevos de encostas íngremes, a taxa de erosão tende a ser maior que a taxa de intemperismo químico. Dessa forma as reações químicas que balizam à alteração de supergênese e consequentemente a formação das lateritas, ficam limitadas.

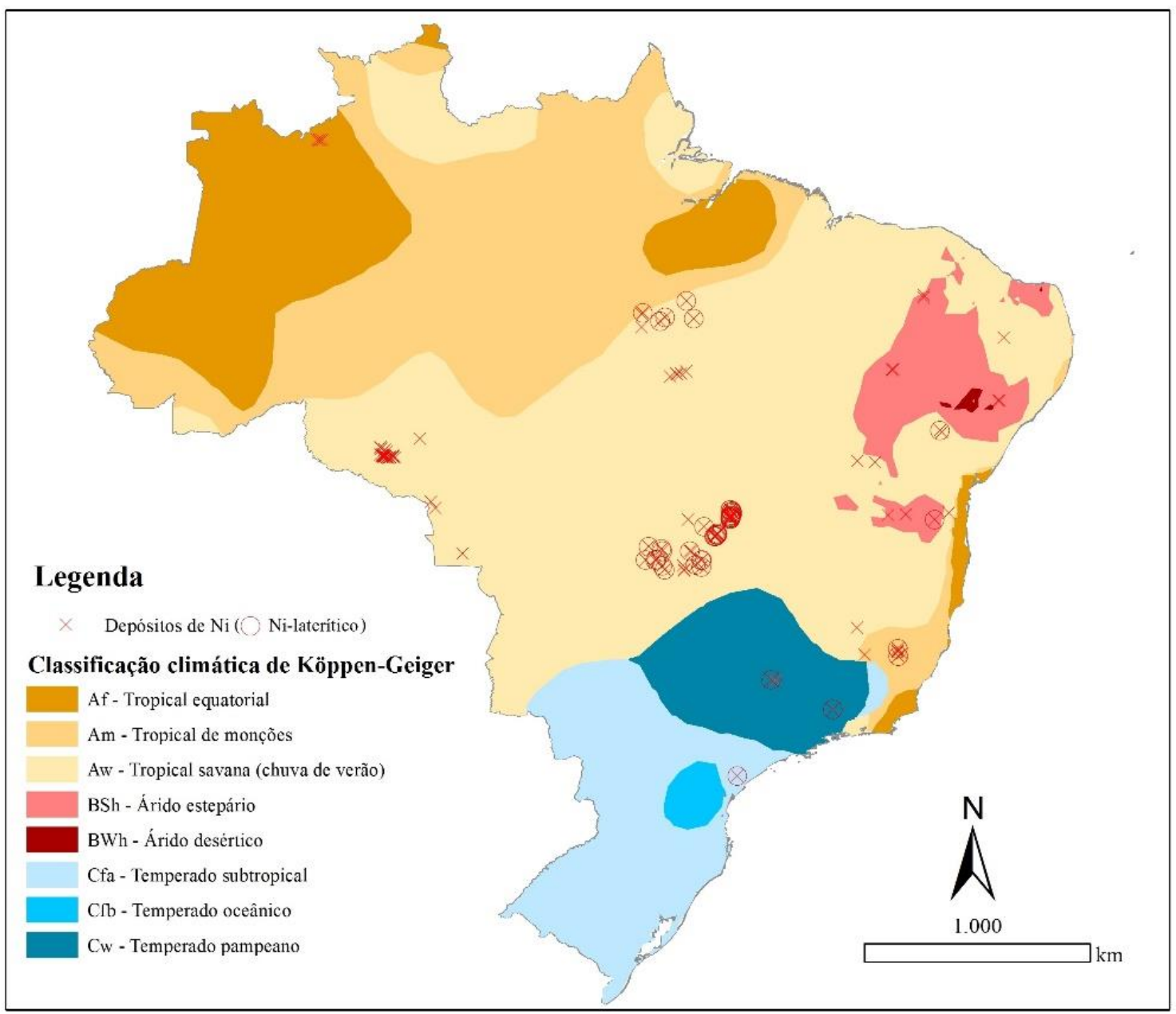

Figura 6. Mapa com a localização das diferentes zonas climáticas brasileiras, segundo classificação de Köppen-Geiger, e as principais ocorrências de níquel. Fonte dos dados: CPRM (2001) e Peel et al. (2007). 


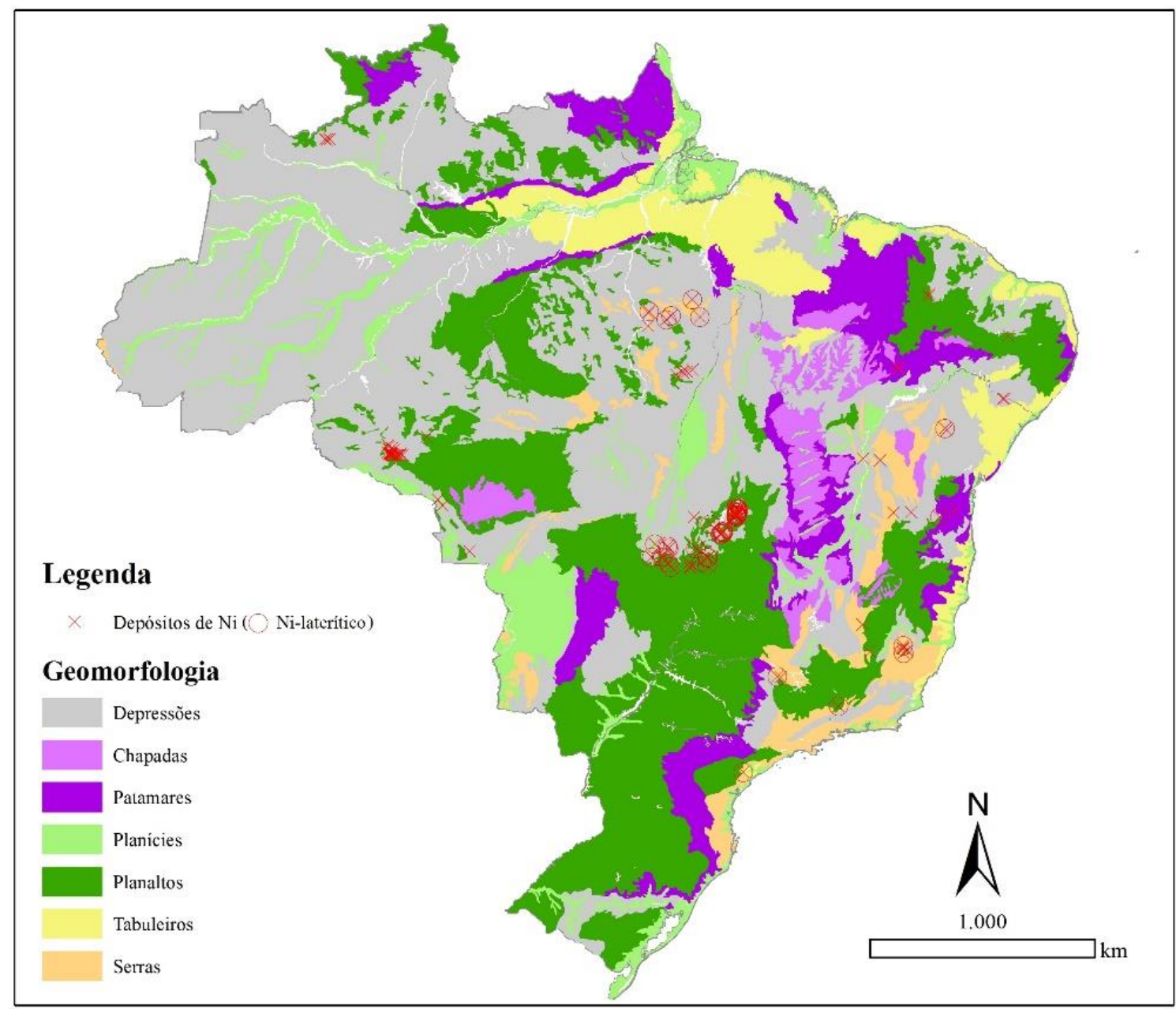

Figura 7. Mapa com a localização das diferentes zonas geomorfológicas brasileiras e as principais ocorrências de níquel. Fonte dos dados: CPRM (2001) e IBGE (2015).

Baseado no conceito de sistema mineral foi efetuado um fluxograma que destaca os principais aspectos do processo mineralizador do Ni laterítico, presente na Figura 8. A janela crítica da formação dos depósitos lateríticos de níquel do Brasil, em boa parte do território, estão relacionadas aos perfis de aplainamento com a existência do clima tropical, com certas variações, desde o início do Cenozoico. Um exemplo onde não houve esse evento crítico foi o escudo Sul-Riograndense, que apesar de possuir rochas ultramáficas com potencial para depósitos de níquel, por ter passado por um clima mais ameno durante o Cenozoico, não ocorreram processos de lateritização suficiente para a formação de lateritas niquelíferas. Outro exemplo se encontra no contexto da Província Borborema, que apesar de hospedar rochas ultramáficas e ter existido climas mais úmidos no Cenozoico (Lima, 2008), também não ocorrem grandes depósitos lateríticos de níquel, salvo exceções. A lateritização nessa região foi restrita, por efeito do clima dominantemente semi-árido e desenvolvimento de intemperismo predominantemente físico.

As lateritas brasileiras carecem de informações geocronológicas de datação absoluta. Esse fato, de certo modo, dificulta a interpretação delas na variação temporal, no decorrer do Cenozoico e das características mais específicas do clima da época, como períodos de estiagem e precipitação média, por exemplo. Lima (2008) datou 
diversos perfis de intemperismo da Província Borborema pelo método ArAr e U-Th/He afim de definir os limites geocronológicos da evolução geomorfológica do nordeste brasileiro. Os minerais datados foram óxidos de manganês surpegênicos (Ar-Ar), e óxidos/hidróxidos de ferro supergênicos (U-Th/He). Os métodos, restritos a alguns poucos trabalhos em lateritas brasileiras, se mostraram eficazes e revelaram que a complexidade $\mathrm{e}$ profundidade dos perfis refletem a duração da exposição destes perfis às condições intempéricas. As idades obtidas registram uma história de intemperismo que vai desde o Eoceno até o Pleistoceno.

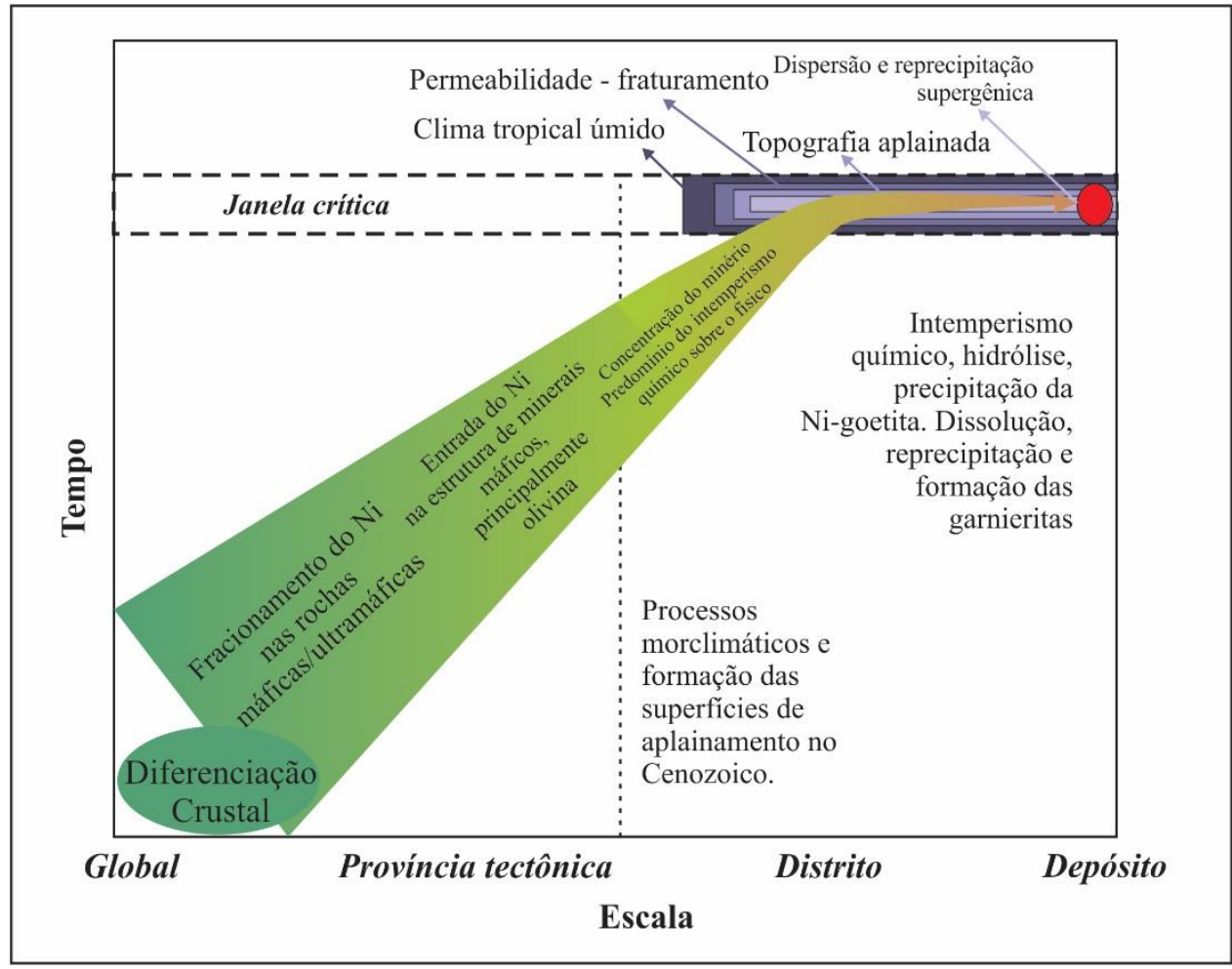

Figura 8. Fluxograma modificado de Bettencourt et al. (2016) e Huston et al. (2016), com proposta de modelo de sistema mineral do Ni laterítico do Brasil.

\section{CONCLUSÕES}

Foi possível definir as características genéticas das lateritas niquelíferas brasileiras, através do conceito de sistema mineral, mesmo que muitas dessas formações possuam certa singularidade. Os protólitos formados pela diferenciação crustal do território brasileiro se relacionam principalmente ao evento Transamazônico, como as Províncias Sunsás e Carajás (intrusões acamadadas), que correspondem aos mais antigos que se tem registro do Brasil, a algumas intrusões proterozoicas consolidadas no ciclo Brasiliano como
Niquelândia e os ofiolitos das faixas móveis. O enriquecimento inicial do níquel se associa aos primeiros minerais que se cristalizaram nessas rochas. Entretanto é bastante complexo inferir como se deu esse fracionamento de forma genérica, principalmente devido à especificidade intrínseca da evolução geoquímica de cada protólito. As rochas duníticas, com maior concentração de olivina, parecem ser as mais propícias ao desenvolvimento de perfis mais significativos. Esse enriquecimento inicial pode ainda ser modificado pela serpentinização e outros eventos metassomáticos e hidrotermais, que 
devem ser estudados, caso a caso, porque podem se relacionar a eventos deformacionais de diferentes escalas e naturezas.

As lateritas niquelíferas brasileiras correspondem à remanescentes dos mantos de alteração das superfícies de aplainamento, que se formaram a partir do Cenozoico, onde devido, basicamente, ao clima tropical úmido, o intemperismo químico atuou e prevaleceu sobre o físico. Essa alteração química é representada principalmente pela hidrólise dos silicatos primários em ambiente oxidante e em seguida, pela remobilização do níquel e precipitação de minerais secundários de níquel junto ao saprólito grosseiro, seja como garnieiritas, esmectitas ou até mesmo serpentinas. Ciente disso, é possível traçar um paralelo entre as superfícies de aplainamento, com a atual configuração da paisagem. Através da interpretação da evolução geomorfológica regional, parece ser possível localizar os correspondentes lateríticos niquelíferos, não sucumbidos pela drenagem, que foram preservados na topografia.

Regiões de destaque para futuras pesquisas e que apresentam aspectos favoráveis segundo fluxograma de sistema mineral do níquel laterítico produzido (Figura 8), são a porção centro-leste do estado da Bahia, sudeste e extremo norte do Tocantins e norte de Roraima. A porção centro-leste do estado da Bahia possui diversos corpos metamáficos e metaultramáficos na zona climática tropical de savana e no domínio geomorfológico de depressões, orientados na direção N-S (Fig. 5) e, portanto, favoráveis a formação de lateritas niquelíferas. A única ocorrência catalogada na região é a da Serra das Marrecas (CPRM, 2001). Intrusões máficas-ultramáficas Tipo Gameleira presentes ao sul do estado do Tocantins também estão inseridas na zona climática tropical de savana e no domínio geomorfológico de depressões, no entanto, nenhuma ocorrência de níquel ainda foi catalogada na região segundo dados da CPRM (2001), e pode ser uma área potencial para novas pesquisas. $\mathrm{O}$ extremo norte do Tocantins, divisa com Pará, possui rochas intrusivas máficas-ultramáficas tipo Quatipuru, que apesar de estarem localizadas no domínio geomorfológico de serras, apresenta-se como área potencial. Roraima apresenta as Suítes Serra da Estrutura e Tapuruquara, que associadas ao clima tropical podem apresentar ocorrências de Ni laterítico. A Suíte intrusiva Figueira Branca localizada no sudoeste do estado do Mato Grosso é também uma área potencial, tendo sido descrita apenas a ocorrência do Rio Aguapei (CPRM, 2001). Remanescente ofiolíticos localizados nas Províncias Mantiqueira e Tocantins são também importantes alvos para futuras pesquisas. Em menor proporção, remanescentes ofiolíticos da Província Borborema não devem ser descartados como alvos de pesquisa, uma vez que o clima úmido já foi predominante na região durante parte do Cenozoico. Nessa região, porções de Serra e de relevo menos dissecados apresentam maior potencial.

McCuaig et al. (2010) sugere que, para a aplicação de sistemas minerais na exploração mineral, é necessário a determinação de critérios mapeáveis que podem ser usados para detectar os elementos do sistema mineral. Os principais critérios são exibidos nos mapas das Figuras 5, 6 e 7: ocorrências de rochas máficas-ultramáficas, clima tropical ou equatorial, relevo preferencial do tipo depressões ou planaltos, e secundariamente tipo serras.

\section{REFERÊNCIAS}

Angeli, N. 1988. Pesquisa dos jazimentos de Níquel e geologia da Folha Ipanema - Minas Gerais. 
Tese de doutorado, Universidade de São Paulo, 290p.

Arndt, N., Ganino, C.M. 2012. Metals and Society: An Introduction to Economic Geology. Springer Science \& Business Media, 160p.

Barnes, S.J., Cruden, A.R., Arndt, N.T., Saumur, B.M. 2016. The mineral system approach applied to magmatic $\mathrm{Ni}-\mathrm{Cu}-\mathrm{PGE}$ sulphide deposits. Ore Geology Reviews. 76:296-316.

Barnes, S.J., Osborne, G.A., Cook, D., Barnes, L., Maier, W.D., Godel, B., 2011. The Santa Rita nickel sulfide deposit in the Fazenda Mirabela intrusion, Bahia, Brazil: geology, sulfide geochemistry, and genesis. Economic Geology. 106(7):1083-1110.

Berger, V.I., Singer, D.A., Bliss, J.D., Moring, B.C. 2011. Ni-Co Laterite Deposits of the World - Database and Grade and Tonnage Models. U.S. Geological Survey Open-File report 2011-1058. 26 p. Disponível em:

https://pubs.usgs.gov/of/2011/105 8/. Acesso em jul. 2019.

Bettencourt, J.S., Juliani, C., Monteiro, L.V.S. 2016. Exploração mineral no Brasil: uso de modelos de depósitos minerais e sistemas minerais. In: Melfi, A.J., Misi, A., Campos, D.A., Cordani, U.G. (Eds) Recursos Minerais no Brasil: problemas e desafios. Academia Brasileira de Ciências, p.176-189.

Biondi, J.C. 2015. Processos metalogenéticos e os depósitos minerais brasileiros. São Paulo: Oficina de Textos, 552p.

Brand N.W., Butt C.R., Elias M., 1998. Nickel laterites: classification and features. Journal of Australian Geology \& Geophysics. 17(4): 8188.

Burns, R.G., 1970. Mineralogical applications of Crystal Field
Theory. Cambridge Univ Press, Cambridge. 523p.

Butt, C.R.M., Cluzel, D. 2013. Nickel laterite ore deposites: weathered serpentinites. Elements. 9:123128.

Colin, F., Nahon, D., Trescases, J.J., Melfi, A.J. 1990. Lateritic weathering of pyroxenites at Niquelândia, Goiás, Brazil: the supergene behavior of nickel. Economic Geology. 85(5):10101023.

Corrêa, A.C.B., Mendes, I.A. 2002. O problema das superfícies de erosão: novas abordagens conceituais e metodológicas. Revista de Geografia, DCG/UFPE. 18(2):70-86.

Costa, M.L. 2007. Introdução ao intemperismo laterítico e à lateritização. In: Licht, O.A. B., Mello, C.S.B., Silva, C.R. (Eds) Prospecção geoquímica de depósitos minerais metálicos, não metálicos, óleo e gás. São Paulo, SBGq/CPRM, p.199-244.

Cox, D.P., Singer, D.A. 1986. Mineral Deposit Models: U.S. Geological Survey Bulletin, 379p.

CPRM, Serviço Geológico do Brasil. 2001. Mapa geológico do Brasil, escala 1:5.000.000. Brasília, Ministério de Minas e Energia.

Dardenne, M.A., Schobbenhaus, C. 2003. Depósitos minerais no tempo geológico e épocas metalogenéticas. In: Bizzi, L. A., Schobbenhaus, C., Vidotti, R. M., Gonçalves, J. H. (Eds) Geologia, Tectônica e Recursos Minerais do Brasil. CPRM, Brasília, p.365448.

DNPM, Departamento Nacional de Produção Mineral. 2009. Economia Mineral do Brasil. Coordenação Antônio Fernando da Silva Rodrigues. Brasília, 764p.

DNPM, Departamento Nacional de Produção Mineral. 2018. Sumário 
Mineral / Coordenadores Thiers Muniz Lima, Carlos Augusto Ramos Neves. Brasília, 131p.

Evans, A.M., Moon, C.J. 2006. Mineral Deposit Geology and Models. In: Moon, C. J., Whateley, M. K. G., Evans, A. M. (Eds) Introduction to mineral exploration, 2, p.36-46.

Ferreira Filho, C.F., Cançado F., Corrêa, C., Macambira, E.M.B., Junqueira-Brod, T.C., Siepierskil, L. 2007. Mineralizações estratiformes de PGE-Ni associadas a complexos acamadados em Carajás: os exemplos de Luanga e Serra da Onça. In: Rosa-Costa, L.T., Klein, E.L., Viglio, E.P. (Eds) Contribuições à geologia da Amazônia. Belém: SBG-Núcleo Norte, v. 5, p.1-14.

Figueiredo, B.R. 1992. Modelos de depósitos minerais. Boletim IGUSP, Série Científica. 23:75-95.

Fonseca, M.J.G., Derze, G.R., Barreto, A.M., Williams, G.H. 1998. Mapa Geológico do Estado do Rio de Janeiro: escala 1:400.000. Rio de Janeiro: DNPM, 1998. 141p.

Fuck, R.A., Jardim Sá, E.F., Pimentel, M.M., Dardenne, M.A., Soares, A.C.P. 1993. As Faixas de Dobramentos Marginais do Cráton do São Francisco: Síntese do conhecimento. In: Dominguez, J.M.L., Misi, A. (Eds) O Craton do São Francisco, Sociedade Brasileira de Geologia, p.161-185.

Golightly, J.P. 2010. Progress in understanding the evolution of nickel laterites. In: Goldfarb, R.J., Marsh, E.E., Monecke, T. (Eds) The Challenge of Finding New Mineral Resources: Global Metallogeny, Innovative Exploration, and New Discoveries, Volume II. Society of Economic Geologists Special Publication, 15, p.451-475.
Gorayeb, P.S.S. 1989. Corpos serpentiníticos da Faixa Araguaia na região de Araguacema Pequizeiro-Conceição do Araguaia (Goiás-Pará). Revista Brasileira de Geociências. 19(1):51-62.

Groves, D.V., Goldfarb, R.J., Santash, M. 2016. The conjunction of factors that lead to formation of giant gold provinces and deposits in non-arc settings. Geoscience Frontiers. 7:303-314.

Hagemann, S.G., Lisitsin, V., Huston, D. L. 2016. Mineral system analysis: Quo Vadis. Ore Geology Reviews. 76:504-522.

Horizonte Minerals PLC. Vermelho resources. Disponível em: https://horizonteminerals.com/uk/ en/vermelho-resources/. Acesso em maio de 2020.

Huston, D.L., Mernagh, T.P., Hagemann, S.G., Doublier, M.P., Fiorentini, M., Champion, D.C., Jaques, A.L., Czarnota, K., Cayley, R., Skiroow, R., Bastrakov, E., 2016. Tectonometallogenic systems - the place of mineral systems within tectonic evolution, with an emphasis on Australian examples. Ore Geology Reviews. 76:168210.

IBGE. Instituto Brasileiro de Geografia e Estatística. 2015. Compartimentos de relevo, escala 1:5.000.000. Ministério do Planejamento, orçamento e gestão.

King, L.C. 1956. A Geomorfologia do Brasil Oriental. Revista Brasileira de Geografia. 18(2):147-266.

Klein, E.L., Carvalho J.M.A. 2008. Recursos Minerais. In: Vasquez, M.L, Rosa-Costa, L.T. (Org) Geologia e Recursos Minerais do Estado do Pará: SIG, Texto explicativo dos Mapas Geológico e Tectônico e de Recursos Minerais do Estado do Pará. Escala 1:1.000.000. Belém: CPRM. 
Lelong F., Tardy Y., Grandin G., Trescases J.J., Boulange B. 1976. Pedogenesis, chemical weathering and processes of formation of some supergene ore deposits. In: Wolf, R.H. (Ed). Handbook of stratabound and stratiform ore deposits, Elsevier, 3, p.92-173.

Lima, M. da G. 2008. A história do intemperismo na Província Borborema Oriental, Nordeste do Brasil: implicações paleoclimáticas e tectônicas. Tese de doutorado, Universidade Federal do Rio Grande do Norte, $251 \mathrm{p}$.

Lima, O.N.B., Valadão, R.C., 2002. Evolução do relevo adjacente à margem continental oriental brasileira: indicadores geológicos. In: Anais do XLI Congresso Brasileiro de Geologia, João Pessoa, 2002.

Louro, V.H.A., Mantovani, M.S.M. Inversão magnética $3 \mathrm{D}$ da anomalia de Morro do Leme (MT). In: Anais $46^{\circ}$ Congresso Brasileiro de Geologia, São Paulo, 2012.

Maia, T.F.A. 2016. Geologia e Litogeoquímica das intrusões máficas-ultramáficas da região de Amajari, Roraima: implicações petrogenéticas. Dissertação de Mestrado em Geociências, Universidade Federal do Amazonas, 100p.

Marsh E.E., Anderson E.D. 2011. Ni-Co laterite deposits: U.S. Geological Survey Open-File Report 20111259.9p.

Matta, G.N.da. 2016. Extração de níquel contido em rocha ultramáficas de depósito Santa Rita (Bahia). Dissertação de Mestrado, Universidade Federal da Bahia, Escola Politécnica, 166p.

McCuaig, T.C., Beresford., S., Hronsky, J. 2010. Translating the mineral systems approach into an effective exploration targeting system. Ore Geology Reviews. 38:128-138.

Melfi A.J., Trescases J.J., Oliveira S.M.B. 1980. Les "laterites" nickeliferes du Brésil. Cahier de Orstom, Série Géologie. 11:15-42.

Melfi, A.J. Misi, A., Campos, D.A. Cordani, U.G. 2016. Recursos Minerais no Brasil: problemas e desafios. Rio de Janeiro, Academia Brasileira de Ciências, 417p.

Melfi, A.J., Carvalho, A., Oliveira, S.M.B., Ribeiro-Filho, E., Formoso, M.L.1988. The lateritic ore deposits of Brazil. Science Géologique Bulletin. 41:5-36.

Mendonça, F.C. 2012. O depósito de classe mundial Serra do Tapa e Vale dos Sonhos: mineralização de níquel laterítico associada a complexos ofiolíticos PréCambrianos da Faixa de Dobramentos Araguaia-Pará, Brasil. Dissertação de Mestrado, Universidade de Brasília, 58p.

Menegotto, E. 2018. Intemperização de rochas ultrabásicas no Rio Grande do Sul, Brasil. Revista Brasileira de Geociências. 13(3):178-189.

Nunes, N.S.V. 2000. Geologia e resultados prospectivos das áreas Morro do Leme e Morro Sem Boné, Mato Grosso. Projeto Platina e Associados. Goiânia, CPRM. 56p.

Oliveira S.M.B., Trescases J.J., Melfi A.J. 1992. Lateritic nickel deposits of Brazil. Mineralium Deposita. 27:137-146.

Oliveira, S.M.B. 1990. Os depósitos de níquel laterítico do Brasil. Universidade de São Paulo, Instituto de Geociências, Concurso para obtenção do título de livredocente. 89 p.

Ollier, C. 1981. Tectonics landforms. Longman, London, 324p.

Paixão, M.A.P. 2009. Complexo ofiolítico Quatipuru, Pará, Brasil. Tese de Doutorado, Instituto de 
Geociências, Universidade de Brasília, 118p.

Paixão, M.A.P., Nilson, A.A. 2002. Fragmentos ofiolíticos da Faixa Araguaia: caracterização geológica e implicações tectônicas. Contribuições à Geologia da Amazônia. 3:85-103.

Peel, M.C., Finlayson, B.L., McMahon, T.A. 2007. Updated world map of the Köppen-Geiger climate classification. Hydrol. Earth Syst. Sci. 11:1633-1644.

Pinheiro, M.A.P., Suita, M.T.F. 2008. Metamorfismo de fundo oceânico e alto grau em meta-peridotitos ofiolíticos neoproterozóicos, Faixa Brasília Sul, Minas Gerais. Revista Brasileira de Geociências. 38:686699.

Queiroga, G.N., Suita, M.T.F., PedrosaSoares, A.C., Martins, M.S., Pinheiro, M.A.P. 2012. Síntese sobre ofiolitos: evolução dos conceitos. REM: R. Esc. Minas. 65(1):47-58.

Riccomini, C., Sant'anna, L.G., Ferrari, A.L. 2004. Evolução geológica do rift continental do sudeste do Brasil. In: Mantesso-Neto, V., Bartorelli, A., Carneiro, C.D.R., Brito-Neves, B.B. (Org) Geologia do continente Sul-Americano: evolução da obra de Fernando Flávio Marques de Almeida, p.383-405.

Ridley, J., 2013. Ore Deposit Geology. Cambridge University Press. 398p.

Ruiz, A.S., Quadros, M.L. do E., Fernandes, C.J., Palmeira, L.C.M., Pinho, F.E.C. 2014. Metalogênese da Província Sunsás. In: Silva, M.G.da, Rocha Neto, M.B.da, Hardy, J., Kuyumjian, R.M. (Eds) Metalogênese das províncias tectônicas brasileiras. CPRM p. 295-304.

Soares, G.A.R., Palermo, N., Pires, F.R.M. 2018. Geochemical and mineralogical characterization of a section through the nickeliferous laterite in Fazenda da Roseta, Liberdade, Minas Gerais, Brazil. Geologia USP, Série Científica. 18(2):201-216.

Souza, T.L., Remus, M.V.D., Dani, N. 2014. Controles mineralógicos e geoquímicos do níquel em rochas ultramáficas no escudo SulRiograndense. Geologia USP, Série Científica. 14(4):81-98.

Strieder, A.J. 2017. Serpentinização e metassomatismo em rochas ultramáficas: discussão das características e recomendações para o tratamento geoquímico. Revista Brasileira de Geociências. 22(3):329-337.

Teixeira N.A., Danni J.C.M. 1979. Petrologia de Lavas Ultrabásicas e Básicas da Sequência VulcanoSedimentar Morro de Ferro, Fortaleza de Minas (MG). Revista Brasileira de Geociências. 9:1518.

Thorne, R.L., Roberts, S., Herrington, R. 2012. Climate change and theformation of nickel laterite deposits. Geology. 40(4):331-334.

Tomazoni Neto, F. 2011. Controle na distribuição das lateritas e saprolitos de alto teor no depósito de níquel laterítico do Jacaré, Distrito de Carajás, Brasil. Dissertação de Mestrado, Universidade Federal do Rio Grande do Sul, Programa de Pósgraduação em Geociências, 215p.

Trescases, J.J. 1997. The lateritic nickelore deposits. In: Paquet, H., Clauer, N. (Eds) Soils and sediments. Springer, Berlin, Heidelberg, p.125-138.

Tuller, M. 2000. Projeto Leste: Folha Ipanema - SE.24-YC-IV, escala 1:100.000. Belo Horizonte: SEME/COMIG/CPRM, v. 26, $70 \mathrm{p}$.

Wicks, F.J., Whittaker, E.J.W. 1977. Serpentine textures and 
serpentinization. The Canadian Mineralogist. 15(4):459-488.

Wyborn, L.A.I., Heinrich, C.A., Jaques, A.L. 1994. Australian Proterozoic mineral systems: essential ingredients and mappable criteria. In: Australian Institute of Mining and Metallurgy Annual Conference, Melbourne, Proceedings, p.109-115.
Zhao, J., Zuo, R., Chen, S.,Kreuzer, O.P. 2015. Application of the tectonogeochemistry method to mineral prospectivity mapping: a case study of the Gaosong tinpolymetallic deposit, Gejiu district, SW China. Ore Geology Reviews. 71:719-734. 